\title{
VII European Paediatric Rheumatology Congress: Annual Scientific Meeting of PRES
}

\author{
23-27 September 2000, Geneva, Switzerland \\ Organised by: Swiss Working Group for Paediatric Rheumatology \\ Centre Multisite Romand de Rhumatologie Pédiatrique \\ Under the Patronage of: Swiss Society of Paediatry \\ Swiss Society of Rheumatology \\ Scientific counselling provided by the International Scientific Advisory Board, chaired by Patricia Woo, President of PRES \\ Honorary President: Anne-Marie Prieur, Paris
}

Dear future members of PRES, friends, and colleagues The Paediatric Rheumatology European Society (PRES) was conceived in 1997 in Garmisch and was officially founded last year in Glasgow. The VIIth European Paediatric Rheumatology Congress will be the first annual meeting of our society. It will be a special pleasure for us to welcome you in Geneva in September 2000.

"From pathogenesis to therapy in paediatric rheumatology: a challenge for the new decade" is the title of our scientific event. As we learnt in Glasgow, the long term outcome of paediatric rheumatic diseases may be accompanied by physical as well as social disabilities in a significant proportion of our patients, certainly many more than we had previously thought. Our common aim is to improve outcome, hence the need to work together to increase our knowledge, to learn from each other, and to have the opportunity to discuss important clinical issues. This is the aim of our new society and its annual meetings.

This congress, at the turn of the decade, will be a good occasion to assess what stage pathogenesis and treatment of the disease has reached. Our hope is that the coming decade will bring us new insights into the pathogenesis of paediatric rheumatic diseases and that the promised new treatments will significantly improve the outcome of our patients. We expect that by 2010, the work of the participants of this congress, the members of PRES, and other scientists will have made significant advances. We set ourselves this challenge for the new decade, not only for the new century or new millennium.
This congress will offer you state-of-the-art lectures on the pathogenesis of rheumatic diseases and future treatments, sessions on juvenile dermatomyositis, scleroderma, osteoporosis, and growth retardation. We will have two forums: one in which young investigators will present and discuss their continuing research; the second in which clinical data on the new classification of juvenile arthritis will be discussed.

We await your scientific contribution, which could be presented either during the sessions or as a poster. This meeting will be a success only if you come with your scientific work, your experience, or your special case reports to share with your colleagues.

On 25 and the 26 September the allied health professionals and social leagues will have their own sessions. The discussions will focus on two different concepts of physiotherapy and quality of life. On the last day will be the joint course for paediatric rheumatology sponsored by both the Swiss Society of Paediatry and the Swiss Society of Rheumatology.

Geneva and Switzerland are happy to welcome you to the VIIth European Paediatric Rheumatology Congress. Besides science, we are sure you will enjoy our beautiful city and our cheerful country. After the heat of the summer, September is a lovely month to discover our mountains, lakes, and historical cities. We are looking forward to seeing you in Geneva from 23 to 27 September 2000.

On behalf of the national organising committee:

MICHAËL HOFER Conference chairman

\section{Basic research}

1.1 Disease specific divergence of $T$ cell receptor (TCR) oligoclonality in juvenile idiopathic arthritis (JIA)

L WEDDERBURN, A PATEL, H VARSANI, P WOO

Department of Molecular Pathology, University College London, UK

Email:l.wedderburn@ucl.ac.uk

We used a highly sensitive molecular heteroduplex technique to track specific clonality of TCR expressed by synovial $\mathrm{T}$ cells from children with JIA. ${ }^{1}$ We observed nonoverlapping oligoclonality compared with peripheral $\mathrm{T}$ cells, with large clonal expansions which may be identical in different joints and persist over several years. Although synovial T cells have a highly activated phenotype (mostly CD45RO+ and HLA-DR+), we showed that the oligoclonal patterns differ from $\mathrm{CD} 45 \mathrm{RO}+$ cells in peripheral $\mathrm{T}$ cells. We also showed that dominant synovial $\mathrm{T}$ cell clones from children with oligoarticular JIA are in the CD4+ population, whereas in children with
HLA-B27+ (enthesitis-related) arthritis large $\mathrm{T}$ cell clones dominate in the CD8+ population. Sequencing and reanalysing the whole TCR repertoire with N-region-specific sequences confirmed that these clones are at a very low frequency (less than 1 in 50000 cells) in peripheral blood. This unexpected divergence is now being investigated at the level of antigen-specific $\mathrm{T}$ cells using major histocompatibility complex/peptide tetramers.

Supported by the Wellcome Trust, UK

1 Int Immunol 1999;11:535.

\subsection{Serum and synovial fluid} concentrations of vascular endothelial growth factor (VEGF) in juvenile idiopathic arthritis (JIA)

$S$ VIGNOLA ${ }^{\star}$, F SABATINI $\dagger$, F FALCINI $\neq$, P PICCO ${ }^{\star}$, A BUONCOMPAGNI*, A LOY ${ }^{\star}$, M GATTORNO ${ }^{\star}$

*2nd Division of Paediatrics, +1 st Division of Paediatrics, G Gaslini Institute, Genoa; $\neq$ Clinic of Paediatrics, University of Florence, Italy
Background-VEGF is a potent endothelial cell-specific mitogen as well as an angiogenic and vascular permeabilising cytokine. Recently, several studies indicated its involvement in the pathogenesis of synovitis in rheumatoid arthritis (RA) as an important agent for neoangiogenesis and changes in vascular permeability of synovial RA pannus.

Objective - To examine the role of VEGF in the pathogenesis of synovitis in JIA.

Patients and methods-Serum samples from 30 patients affected with active JIA (14 poly, 26 oligo) were evaluated with ELISA for VEGF (Amersham, UK) and p75 tumour necrosis factor soluble receptor (sTNFR) (Medgenix, Belgium) concentration. Corresponding VEGF and p75 sTNFR synovial fluid $(\mathrm{SF})$ concentrations were evaluated in 20 patients. Data were compared with those from 10 patients with oligo-JIA in the remission phase and 10 controls.

Results - In patients with active poly-JIA and oligo-JIA, the VEGF SF concentration (median $637.5 \mathrm{ng} / \mathrm{ml}$; range 158-2000) was significantly higher than the corresponding serum concentration (median $111.5 \mathrm{ng} / \mathrm{ml}$; 
range 47-1081) $(p<0.05$, Wilcoxon rank test). Serum VEGF concentrations in active poly-JIA (median $315.5 \mathrm{ng} / \mathrm{ml}$; range 741895) were significantly higher than those in active oligo-JIA (median $92.0 \mathrm{ng} / \mathrm{ml}$; range 47-1081) ( $\mathrm{p}=0.009$, Mann Whitney U test), inactive JIA (median $123.0 \mathrm{ng} / \mathrm{ml}$; range 86-265) $(\mathrm{p}=0.02)$, and healthy controls (median $51 \mathrm{ng} / \mathrm{ml}$; range 44-269) $(\mathrm{p}=0.01)$. The VEGF serum concentration showed a weak significant correlation with white blood cell count, erythrocyte sedimentation rate, and, inversely, with haemoglobin concentration but not with serum p75 sTNFR. Conversely, the SF VEGF concentration showed a strong positive correlation with $\mathrm{p} 75$ sTNFR $(r=0.86, p=0.001)$.

Conclusion-These data show the prominent local role of VEGF at the site of inflammation during active synovitis in JIA. This particular issue might be related to active neangiogenesis processes occurring during pannus formation.

1.3 Tumour necrosis factor $\alpha \mathrm{G} \rightarrow \mathrm{A}$ polymorphisms in juvenile idiopathic arthritis

M ALIKASIFOGLU, A BAKKALOGLU, A DUZOVA, N BESBAS, E TUNCBILEK, $S$ OZEN

Department of Paediatric Rheumatology and Genetics, Hacettepe University, Ankara, Turkey Background-Tumour necrosis factor a $(\mathrm{TNF} \alpha)$ is a cytokine that has been frequently implicated in the process of inflammation. Polymorphisms that have been defined in the gene for $T N F \alpha$, have been associated with the course of certain disease states, such as ankylosing spondylitis.

Objective-To assess whether the $238 \mathrm{G} \rightarrow \mathrm{A}$ polymorphism in the promoter of the TNFo gene is associated with the type of juvenile idiopathic arthritis (JIA) and severity of the disease.

Patients and methods - The types of JIA in the study group were classified as $31.8 \%$ oligoarticular, $11.4 \%$ extended oligoarticular, $38.6 \%$ polyarticular, and $18.2 \%$ systemic type Ninety three healthy young volunteers served as controls for the population. DNA was extracted from whole blood and the 238 $\mathrm{G} \rightarrow \mathrm{A}$ TNF $\alpha$ polymorphism was analysed using the $\mathrm{F}$ and $\mathrm{R}$ primer pairs, followed by digestion with the restriction enzyme BamHI The severity of the disease at the end of one year in each patient was evaluated on the basis of a severity score, by the caring physician. The mean age of the patients was 7.9 years (range 1-16). Half the patients were girls. Results - Table 1 shows the allele distribution for the aforementioned TNF $\alpha$ polymorphism in patients with JIA and controls.

Table 1 Allele distribution. Results are shown as number (\%)

\begin{tabular}{llll}
\hline \multirow{4}{*}{ Subjects } & \multicolumn{3}{l}{ Genotypes } \\
\cline { 2 - 4 } & $G G$ & $G A$ & $A A$ \\
\hline Patients with JIA & $37(74)$ & $12(24)$ & $1(2)$ \\
Controls & $68(73)$ & $22(24)$ & $3(3)$ \\
\hline
\end{tabular}

The frequencies were not different $(p>0.05)$. Thus we could not detect an association between the $238 \mathrm{G} \rightarrow \mathrm{A}$ TNF $\alpha$ polymorphism and patients with JIA. A study of another polymorphism in the promoter region and correlation with severity is underway.

This study was supported by the Scientific and Technical Research Council of Turkey.
1.4 Apoptosis in familial Mediterranean fever

S OZEN, D UCKAN, E BASKIN,

N BESBAS, U SAATCI,

A BAKKALOGLU

Hacettepe University Faculty of Medicine,

Ankara, Turkey

Background-Apoptosis is a programmed form of cell death.

Objective - To analyse the role of apoptosis in the inflammatory pathway of familial Mediterranean fever (FMF).

Patients and methods-Nineteen patients with FMF and 10 age and sex matched controls were the subject of the study. Eleven of the patients were analysed during an FMF attack whereas samples were obtained at least a week after an attack in eight. Whole blood was treated with ammonium chloride for red blood cell lysis. Subsequently, the cells were stained with propidium iodide and annexin. Neutrophils and lymphocytes were gated separately for analysis by flow cytometry.

The mean (SD) age of the patients was 12.0 (3.57), and did not different from that of the control subjects.

Results-Erythrocyte sedimentation rate and C reactive protein levels were significantly raised in the attack group as compared with the attack-free group. The mean (SD) levels of neutrophil apoptosis in the patients with FMF with an attack, attack-free, and controls were 19.52 (16.41), 9.18 (11.01), and 7.40 (4.92), respectively. Lymphocyte apoptosis in the same groups was 4.46 (7.88), 1.63 (3.16), and 0.18 (0.15), respectively. Neutrophil apoptosis was significantly increased in patients during an attack as compared with the attack-free patients and with the controls $(p<0.05)$. However, lymphocyte apoptosis did not differ between the groups. Apoptosis was also significantly increased in the patients with amyloidosis when analysed separately $(\mathrm{p}<0.05)$.

Conclusion-Neutrophil but not lymphocyte apoptosis was significantly increased during FMF attacks reminding us that FMF is an autoinflammation of the neutrophils. The increased apoptosis in these patients may be regarded as a response to clear the unwanted inflammatory neutrophils. On the other hand, the increased apoptosis may be an explanation of the self limiting nature of FMF attacks. Future studies will enlighten us on the significance of this increased apoptosis in the process of inflammation.

\subsection{Role of apoptosis in childhood leucocytoclastic vasculitis}

F OZALTIN, N BESBAS, D UCAR, M TUNCER, S OZEN, R TOPALOGLU, A BAKKALOGLU

Hacettepe University Faculty of Medicine, Departments of Paediatric Nephrology and Rheumatology and Paediatric Hematology, Ankara, Turkey

Background-Pathogenesis of vasculitis is complex and not yet fully elucidated, but inflamatory cells have a major role. Dysregulation of apoptosis and clearance of inflammatory cells might lead to the persistence of inflammation and excessive tissue injury.

Objective-To investigate fas and fas ligand expression and apoptosis on neutrophil leucocytes, monocytes, and lymphocytes in leucocytoclastic vasculitis in the acute phase and after remission.

Patients and methods-Leucocytoclastic vasculitis presenting with Henoch-Schönlein purpura (HSP) was diagnosed according to
ARA criteria and confirmed by skin biopsy Thirty seven patients ( 22 boys, 15 girls), aged 2.5-17 years (mean (SD) 9 (3.3)) were enrolled. All patients presented with the characteristic palpable purpuric lesions of HSP. Twenty five $(68 \%)$ and $9(24 \%)$ had arthritis/arthralgia and gastrointestinal disease, respectively. Twelve (32\%) had renal disease (haematuria and/or proteinuria). The mean (SD) erythrocyte sedimentation rate and $C$ reactive protein were $49(26) \mathrm{mm} / 1 \mathrm{st} \mathrm{h}$ and $25(30.3) \mathrm{mg} / \mathrm{l}$, respectively during acute phase and returned to normal in all during remission. Patients were divided into two groups. In one group fas and fas ligand expression on neutrophil, monocyte, and lymphocyte was studied by flow cytometry and in the other group apoptosis in peripheral blood by the annexin method was studied in the acute and remission periods. In group 1, 10 boys and 7 girls, aged 10.2 (3.7) years (range 4.5-17) were enrolled. The mean neutrophil, monocyte, and lymphocyte CD95 expression was $65.4(37.6) \%, 89.5$ (9.5)\%, and $33.3(7.3) \%$, respectively, in the acute stage while the mean (SD) values were $62.8(44.2) \%, 70.8(30.6) \%$, and $41(20) \%$, respectively, in remission ( $\mathrm{p}>0.05)$. For fas ligand, these values were $75.2(31.8) \%, 71.3$ (28.4)\%, and 58.0 (35.9), respectively, in the acute stage and $87.8(22.0) \%, 81.4(22.7) \%$, and $30.8(32.35) \%$ in remission $(\mathrm{p}>0.05)$. In group 2,12 boys and 8 girls aged $8(2.6)$ years (range 2.5-12) were enrolled. Total neutrophil, monocyte and lymphocyte apoptosis were $13.3(11.31) \%, 23.2(21.1) \%$, and 8.6 (9.5)\%, respectively, during the acute phase and $4.6(3.4) \%, 10.3(9.9) \%$, and $3.1(3.1) \%$, respectively, in remission $(p=0.002, p=0.019$, $\mathrm{p}=0.008$ ).

Conclusion-These results suggest that apoptosis may have an important role in early control of the inflammatory response and repair in leucocytoclastic vasculitis.

1.6 Expression of calcium-binding proteins MRP8 and MRP14 in polymyositis and inflammatory muscle diseases

S SEELIGER ${ }^{\star}$, C SUNDERKÖTTER†, C SORG $\ddagger$ J ROTH*

${ }^{*}$ Department of Paediatrics, + Department of Dermatology, $\neq$ Institute of Experimental

Dermatology, University Münster, Germany Background-Idiopathic inflammatory myopathy (IM) encompasses a heterogeneous group of muscle diseases. A classification in three main groups has been established $(a)$ dermatomyosites (DM), including childhood DM; (b) polymyositis (PM); and (c) inclusion body myositis (IBM). PM and DM are considered to be autoimmune diseases with $\mathrm{T}$ lymphocyte mediated muscle damage. IM is characterised by the presence of mononuclear cell infiltrates in muscle tissue. The pathological role of monocytes, however, is not yet clear. Monocytes in inflammatory lesions often express calcium-binding proteins (MPR8 and MRP14) of the S100 family.

Methods-We investigated the expression and local distribution of MRP8 and MRP14 in IM. Muscle biopy samples from 28 patients were analysed immunohistochemically.

Results - Nine patients had the typical features of DM, 12 patients of PM, and in 7 patients the diagnosis of IBM was established by electron microscopy. In DM, PM, and IBM endomyosial mononuclear infiltrates consist of lymphocytes (B and $\mathrm{T}$ cells), monocytes, and macrophages (CD68); these cells surround and may invade non-necrotic myofibres. In contrast, MRP8 and MRP14 
expressing monocytes are the most abundant cell type in necrotic myofibres. This finding was confirmed by double-labelling experiments (MRP8 or MRP14 and CD68). This pattern of infiltrating cells was similar in all three disorders.

Conclusion-Our results suggest that activated monocytes are a destructive component beside T lymphocyte mediated muscle damage in the inflammatory process of IM. The expression of MRP8 and MRP14 correlate with disease activity and destruction of muscle in IM.

\subsection{MRP8 and MRP14 are specific} markers for inflammatory activity in juvenile idiopathic arthritis (JIA)

J ROTH, M FROSCH, A STREY, N WULFFRAAT, T VOGL, C SUNDERKÖTTER, W KUIS,

\section{E HARMS, C SORG}

Department of Paediatrics and Institute of

Experimental Dermatology, University of Münster, Germany; Wilhelmina Children's Hospital,Utrecht, Netherlands

Background-MRP8 and MRP14 are two calcium-binding proteins which are constitutively expressed by neutrophils and monocytes. Serum concentrations of these proteins correlate with activity of various inflammatory diseases.

Methods - We analysed a coculture system of endothelial cells and monocytes.

Results-We showed that MRP8 and MRP14 are specifically released during interaction of activated monocytes with tumour necrosis factor-stimulated endothelial cells. Secretion is mediated through an intracellular calcium signal in monocytes. In contrast, adhesion to resting endothelium inhibits protein kinase C-induced release of MRP8/MRP14 by monocytes. In pauciarticular onset JIA MRP8 and MRP14 are strongly expressed in neutrophils and monocytes within the synovial infiltrate and can be found in significantly higher concentrations in synovial fluid $(42800 \mathrm{ng} / \mathrm{ml})$ than in serum $(2060 \mathrm{ng} / \mathrm{ml})$. Serum concentrations of MRP8/MRP14 correlated well with those in synovial fluid and with disease activity. After intra-articular triamcinolone treatment the serum concentrations of MRP8/MRP14 decreased significantly in treatment responders but not in patients resistant to treatment. ${ }^{1}$ Patients with systemic onset JIA showed the highest serum concentrations during active disease (33200 $\mathrm{ng} / \mathrm{ml}$ ), which decreased to the normal range during remission or after bone marrow transplantation (BMT). Interestingly, patients with macrophage activation syndrome after BMT showed an increase of MRP8/MRP14 concentrations. When skin biopsy specimens were analysed during an acute flare of systemic JIA, dermal epithelial cells were identified as an additional source of MRP8/ MRP14 expression beside phagocytes. Thus MRP8 and MRP14 are specifically released during the interaction of monocytes with inflammatory activated endothelium at sites of active inflammation. Their serum concentrations represent a useful marker for monitoring inflammation in JIA. In addition, activation of epithelial cells as shown by expression of MRP8 and MRP14 is a so far unknown pathomechanism during the early phase of systemic JIA

1 Frosch et al. Arthritis and Rheumatism 2000; 43:628-37.
1.8 Genetic predisposition to low interleukin 10 (IL10) production in children with extended oligoarticular juvenile idiopathic arthritis (JIA) and in those with uveitis

ESTHER CRAWLEY, PATRICIA WOO

Department of Molecular Pathology, Windeyer

Building, UCL, London, UK

We have shown that the IL10 5' flanking region ATA haplotype is associated with low IL10 production and that children with the ATA haplotype are twice as likely to develop extended oligoarticular JIA as those with oligoarticular JIA.

To investigate this association further we used the transmission disequilibrium test in 105 families. There was a significant increase in transmission of the ATA haplotype to patients with oligoarticular onset JIA $(p=0.05)$. There was also a significant increase in the transmission of both the ACC and the ATA haplotype to patients with uveitis $(\mathrm{p}=0.014$ each $)$

Having established an association between a low IL10 producing haplotype and children with severe disease, we wanted to know whether children with extended oligoarticular JIA produced less IL10 during inflammation than children with oligoarticular JIA. IL10 production cannot be measured directly in patients because of the treatment they receive. Parental IL10 production was therefore used as a marker for childhood IL10 production as family studies have estimated that $84 \%$ of the variability in IL 10 production is genetically determined.

We showed that mean IL10 production was lower in the parents of those with extended oligoarticular JIA $(n=14$, mean (SE) $2109.2(251)$ ) than those with oligoarticular JIA ( $\mathrm{n}=12$, mean (SE) 3161.7 (411)); the results were significant $(\mathrm{p}=0.034$, $95 \%$ CI 88 to 2016 )

These findings strongly suggest that children with arthritis can have a genetic predisposition to low IL10 production and a concomitant increase in their risk of developing either extended oligoarticualr JIA or uveitis.

This work was funded by the ARC.

1 Arthritis and Rheumatism 1999;42:1101-7.

1.9 Association of low bone mass with vitamin $D$ receptor and calcitonin receptor gene polymorphisms in rheumatic diseases of childhood

F FALCINI ${ }^{\star}$, L MASI + , G SIMONINI*, GB CALABRI* ${ }^{\star}$, S STAGI*, G BINDI*, R CIMAZ $\ddagger$ ML BRANDI $\dagger$

*Paediatrics and +Clinical Physiopathology,

University of Florence; $\neq$ Paediatrics, ICP,

Milan, Italy

Background-Different factors play a part in the pathogenesis of osteoporosis in children with rheumatic disease, and genetic influence may have an important role.

Objective - To evaluate polymorphisms in the calcitonin receptor (CTR) and vitamin D receptor (VDR) genes in 50 patients with rheumatic diseases and 80 controls.

Methods-Bone mineral density (BMD) was measured in patients by dual energy $x$ ray absorptiometry at the lumbar spine. Genomic DNA was isolated from EDTA blood samples by standard procedures. Polymerase chain reaction (PCR) was performed using genomic DNA and 100 pmol of each oligonucleotide primer for VDR and CTR genes. Products from genomic PCR were digested by $A l u \mathrm{I}$ enzyme for CTR polymorphism and FokI enzyme for VDR polymorphism.
Results - In the total group of samples studied, higher prevalences of CC genotype $(41.5 \%)$ for the CTR gene and Ff genotype $(59.8 \%)$ for the VDR gene were found. These data are in agreement with previous data obtained in the white population. No significant differences in the distribution of the CTR and VDR genotypes were found between patients and controls. However, patients with a TT genotype had a BMD $15.2 \%$ lower than patients with a CC genotype $(p=0.04)$. For the VDR gene polymorphism, we found that patients with the ff genotype had a BMD 24\% lower than patients with the FF genotype $(p=0.03)$. These differences did not seem to be related to corticosteroid treatment.

Conclusion-Our data suggest that patients with certain VDR and CTR genotypes may be at higher risk of developing bone loss.

1.10 Expression of toll-like receptor 2 in rheumatoid synovium

REINHART SEIBL $\star$ THOMAS

BIRCHLER ${ }^{\star}$, JOHANN PETER

HOSSLE ${ }^{\star}$, KATJA BÜCHNER ,

SUSANNE LOELIGER ${ }^{\star}$, ELVIRA

JEISY†, RENATE E GAY†, REINHARD

A SEGER ${ }^{\star}$, TRAUDL SAURENMANN*, STEFFEN GAY $\dagger$, ROGER P LAUENER ${ }^{\star}$

${ }^{\star}$ Zurich University, Children's Hospital,

Division for Immunology, Steinwiesstrasse 75, 8032 Zürich, tDepartment of Rheumatology, USZ

Background-Members of the recently described family of mammalian toll-like receptors (TLR) show homology with the Drosophila Toll protein and with the cytoplasmic domain of the interleukin 1 receptor. Human TLR2 has been shown to mediate translocation of NF-KB and the induction of an inflammatory response upon recognition of conserved microbial constituents such as lipopolysaccharide, lipoteichoic acid, and bacterial lipoprotein.

Objective - To investigate whether TLR2 molecules might contribute to synovial cell activation and inflammation in rheumatoid arthritis (RA) by assessing the expression of TLR2 in synovial cells.

Methods-Tissue sections from 7 RA affected joints and 4 healthy subjects were analysed by in situ hybridisation with a digoxigenin labelled RNA probe. The probe was generated as follows: Total RNA was isolated from human whole blood and CDNA was synthesised by reverse transcription. A $443 \mathrm{bp}$ fragment complementary to the sequence coding for the extracellular part of TLR2 was amplified by polymerase chain reaction and cloned into pBluescript KS II (-). Then the probe was synthesised by in vitro transcription in the presence of digoxigenin labelled UTP.

Results-Synovial cells from RA affected joints expressed markedly raised levels of TLR2 mRNA when compared with synovial cells from healthy subjects. TLR2-expressing cells were mainly localised at sites of attachment of the synovium to cartilage and bone. The TLR2 expressing cells were not T cells invading inflamed joints, as shown by double staining with anti-CD3 antibodies. Conclusion-As NF-KB has been shown to be highly expressed in RA synovium, these findings suggest a potential contribution of TLR2 in synovial cell activation and inflammation in RA. 
1.11 Expression of CD14 or HLA-DR enhances cellular activation by lipopolysaccharides and bacterial lipoproteins through toll-like receptor 2 KATJA BÜCHNER, THOMAS BIRCHLER, REINHART SEIBL, DIDIER HEUMANN, SUSANNE LOELIGER, JOHANN PETER HOSSLE, REINHARD A SEGER, ROGER P LAUENER Zurich University, Children's Hospital, Division for Immunology, Steinwiesstrasse 75, 8032 Zurich, Switzerland

Background-Activation of cells by various molecules of microbial origin has been shown to be mediated by toll-like receptors (TLR), whereas expression of CD14 increases cellular responsiveness.

Objective-To assess whether expression of additional molecules might influence responsiveness to the bacterial constituents lipopolysaccharide (LPS) and bacterial lipoprotein (BLP).

Method-293 wild-type human embryonic kidney (HEK) cells or 293 HEK cells stably transfected with CD14, HLA-DR or CD14 and HLA-DR 1 were stimulated with LPS or BLP in the absence and presence of transiently transfected TLR2; cellular activation was measured with a NF-KB dependent luciferase reporter system.

Results-As shown in previous reports, the response to LPS and BLP of 293 cells transfected with TLR2, but not wild-type cells, depended on dose, and additional expression of CD14 increased responsiveness to LPS and BLP as measured by luciferase activity. Here we showed that cotransfection of TLR2 with the $\alpha$ chain, $\beta$ chain, and the invarian chain of HLA-DR1 increases responsiveness to LPS and BLP to a similar extent as cotransfection of TLR2 with the LPS receptor CD14. Triple transfection of 293 HEK cells with TLR2, CD14, and HLA-DR1 did not result in a further increase of responsiveness. Transfection of CD14 or HLA-DR1 in the absence of TLR2 was not sufficient to confer responsiveness to LPS or BLP.

Conclusion-We propose that in addition to their role in antigen presentation and in the initiation of an adaptative immune response, major histocompatibility complex class II molecules modulate the innate immune response.

\section{$1.12 \mathrm{~T}$ cell selection in patients with} early onset pauciarticular JIA

JPP HAAS ${ }^{\star}$, C FRANK ${ }^{\star}$, $S$ FERNANDEZ ${ }^{\star}$, A ZURMÜHL $M$ HERRMANN + , H RUDER $\ddagger$

*Laboratory for Paediatric Rheumatology and Immunology, Department of Paediatrics, Friedrich Alexander University,

Erlangen-Nuremberg, Germany; tInstitute for Clinical Immunology and Rheumatology, Friedrich Alexander University,

Erlangen-Nuremberg, Germany; $¥$ Children's Rheumatology Hospital, Garmisch

Partenkirchen, Germany

Objective-To determine whether evidence exists for a clonal expansion of $\mathrm{T}$ cells in early onset pauciarticular juvenile idiopathic arthritis of childhood (EOPA-JIA)?

Methods-RNA was prepared from peripheral mononuclear cells (PBMC) of 16 patients with EOPA-JIA, 11 healthy controls, and from samples derived from synovial fluids of the patients with JIA. Moreover, some patients and controls were studied longitudinally. The $\mathrm{T}$ cell repertoire was analysed on the basis of the $\beta$ chain variability of the $\mathrm{T}$ cell receptor. A reverse transcriptase polymerase chain reaction based method called Spectratyping, which detects expansions of the CDR3 fragment length polymorphism, was performed to determine expansions in the repertoire representing clonality of $\mathrm{T}$ cells.

Results-Patients with EOPA-JIA showed changes in their T cell repertoire in PBMC as well as in IAMC, but the compartments differed when compared with each other in one subject. Each patient had an individual pattern of changes which persisted up to 17 months in IAMC. The changes in T cell repertoire were found to be oligoclonal and there was no association of a single $V \beta$ family with EOPA-JIA.

Conclusions-There is strong evidence for specific $\mathrm{T}$ cell selection into the arthritic joint in EOPA-JIA. Each patient creates an individual oligoclonal pattern of $\mathrm{T}$ cells.

\subsection{Prolactin promoter polymorphism} and juvenile idiopathic arthritis (JIA)

W THOMSON, E SHELLEY, A STEVENS, J WORTHINGTON, WER OLLIER, RP DONN $A R C / E U$, University of Manchester, England, UK

Background -Prolactin has been shown to be active as an immunomodulatory hormone. Hyperprolactinaemia has been implicated in the cause of some autoimmune diseases. Increased serum levels of prolactin have been found in children with JIA. The prolactin gene is situated on chromosome 6 telomeric to HLA and has two promoter regions (pituitary and lymphoid) which are known to contain functional polymorphisms.

Objectives-To establish whether an association exists between the functional prolactin lymphoid promoter polymorphism and JIA.

Methods-361 children with JIA and 393 controls were typed for the promoter polymorphism using polymerase chain reactionrestriction fragment length polymorphism. Genotype frequencies were compared between all patients and controls and between the different JIA subgroups using the $\chi^{2}$ test. Results-There was no difference in the genotype frequencies between all patients and controls $(p=0.4)$ or between any of the JIA subgroups $(p=0.8)$. Also, genotype frequencies were not significantly different when patients were subdivided by antinuclear antibody status or sex

Conclusions - JIA is not associated with a functional prolactin lymphoid promoter polymorphism

1.14 Tumour necrosis factor receptor II (TNFRII) polymorphism and oligoarticular juvenile idiopathic arthritis (oligo-JIA)

E ZEGGINI, W THOMSON, A ALANSARI, WER OLLIER, RP DONN

$A R C / E U$, University of Manchester, England, UK

Background-JIA is a complex disease with both genetic and environmental factors contributing to its cause. The encouraging outcome of anti-TNF treatment, ${ }^{1}$ as well as serological studies ${ }^{2}{ }^{3}$ have implicated TNF and its receptors (TNFRI and TNFRII) in the pathogenesis of JIA.

Objective-To investigate the exon 6 TNFRII polymorphism. This $\mathrm{T}$ to $\mathrm{G}$ single nucleotide polymorphism (SNP) results in a methionine to arginine amino acid substitution that might be of functional importance to receptor-ligand binding or activation of the downstream pathway.

Patients and methods-We examined a well defined UK cohort of patients with the commonest JIA presentation, oligoarthritis, using case-control (association) analysis. Screening for the $T$ or $G$ alleles was carried out by polymerase chain reaction-restriction fragment length polymorphism, using NlaIII enzyme. Genomic DNA was used from 73 white patients with oligo-JIA and 180 healthy unrelated subjects of the same ethnic origin Results-Table 2 shows the genotypic frequencies obtained.

Table 2 Genotypic frequencies. Results are shown as number (\%)

\begin{tabular}{llll}
\hline & \multicolumn{3}{l}{ Genotype (\%) } \\
\cline { 2 - 4 } & $G G$ & $T T$ & $T G$ \\
\hline Patients $(\mathrm{n}=73)$ & $7(10)$ & $35(48)$ & $31(42)$ \\
Controls $(\mathrm{n}=180)$ & $8(4)$ & $99(55)$ & $73(41)$ \\
\hline
\end{tabular}

No significant differences were seen $(\mathrm{p}=0.24)$.

Conclusions-Future work will focus on increasing the power of the study by typing for more patients with oligo-JIA and also examining the role of this TNFRII SNP in other subgroups of JIA.

1 Furst, et al. Ann Rheum Dis 1999;58:725-6.

Mange, et al. J Interferon Cytokine Res 1999;19:1005-10.

3 Gattorno, et al. Arthritis Rheum 1996;39: 883-4.

1.15 Fas (CD95)-670 promoter polymorphism and juvenile idiopathic arthritis (JIA)

RP DONN, E SHELLEY, WER OLLIER, W THOMSON

ARC/EU, University of Manchester, England, $U K$

Background-Fas (CD95) is a transmembrane protein that is part of the tumour necrosis factor receptor family. Fas mediates apoptosis and hence Fas, together with Fas ligand, has an essential role in immune regulation. Altered mRNA expression of Fas has previously been reported in patients with JIA. ${ }^{12}$ We have studied the -670 promoter polymorphism of FAS. This is an A to G substitution that alters a GAS sequence for STAT transcription factor binding.

Methods - 346 white UK patients with JIA and 166 unrelated healthy controls were studied. Genomic DNA was amplified by polymerase chain reaction and the product digested with MvaI. Comparison of allele and genotype frequencies was made with $\chi^{2}$ tests. Results-No association was found when the allele frequencies of the patients with JIA and the control panel were compared. However, an association was seen when rheumatoid factor (RF) positive patients with JIA were compared with RF negative patients with JIA (table 3).

Conclusions-There is an apparent association between -670 Fas polymorphism and $\mathrm{RF}$ positive JIA. We will increase the number of RF positive patients to be typed for this polymorphism.

1 Sioud M, Mellbye O, Forre O. Clin Exp Rheumatol 1998;16:125-34.

Haas J-P, Frank C, Haefner R. Eur J Immunogenet 1999;26:325-9.

3 Huang QR, Morris D, Manolios N. Mol Immunol 1997;34:577-82. 
Table 3 Allele frequencies (\%) in patients with $\mathcal{F I A}$ and controls, and in RF positive and negative patients with $\mathcal{F I A}$

Fas -670 allele

A

Controls $(2 \mathrm{n}=332)$

Patients with JIA $(2 \mathrm{n}=692)$

$\mathrm{RF}+\mathrm{ve}$ JIA $(2 \mathrm{n}=64)$

RF -ve JIA $(2 n=560)$

$184(55)$
$349(50)$
$24(38)$
$289(51.6)$

G

$p$ Value

1.16 Immunophenotypic profiles of circulating lymphocytes and monocytes in different juvenile chronic arthritis (JCA) subtypes emphasise the heterogeneity of the disease

\section{WOUTERS}

Paediatric Rheumatology, University Hospital Gasthuisberg, Leuven, Belgium

Patients and methods-The immunophenotypic profile of peripheral blood lymphocytes and monocytes was investigated using dua fluorescence flow cytometry in 41 patients - 19 with oligoarticular (o), 10 with polyarticular (p), and 12 with systemic (s) onset JCA-and 41 age matched healthy controls.

Results-Patients with o-JCA and p-JCA had significant expansions of $\mathrm{T}$ cells expressing HLA-DR, CD57, and CD16/56, indicating increased activation and terminal differentiation of $\mathrm{T}$ cells, as has been reported in other immune-inflammatory disorders - for example, HIV infection or allotransplantation. Patients with s-JCA had no increase of activated or differentiated $\mathrm{T}$ cells, but a profound decrease of NK cells. All patients had hypergammaglobulinaemia consistent with $\mathrm{B}$ cell hyperactivity; increased numbers of CD5+ B cells were only found in o-JCA and p-JCA. The activation of circulating monocytes, measured by CD11b/CD18 expression, was increased in s-JCA compared with o-JCA and p-JCA. Accordingly, levels of the monokine interleukin 6 and various acute phase proteins were manifestly increased in patients with s-JCA.

Conclusion - The immmunophenotypic lymphocyte profiles in o-JCA and p-JCA point to the importance of chronic $\mathrm{T}$ cell activation in these subtypes; conversely, our analysis suggests a key role for circulating activated monocytes in the "persistent acute phase response" characteristic of s-JCA.

1.17 Hyperresponsiveness of monocytes from patients with systemic juvenile idiopathic arthritis (sJIA) to interferon $\gamma(\mathbf{I F N} \gamma)$

R TEN CATE ${ }^{\star}$, AJM FRENKEN ${ }^{\star} \dagger$, S MELMAN ${ }^{\star} \dagger$, E RAVENSBERGEN $\dagger$, $M$ TEN DAM ${ }^{\star}$, DMC BRINKMAN* MJD VAN TOL, PH NIBBERING $\dagger$ Departments of ${ }^{*}$ Paediatrics and +Infectious Diseases, Leiden University Medical Centre, Leiden, The Netherlands

Macrophage activation syndrome (MAS) is a life threatening complication in transplant patients with systemic juvenile idiopathic arthritis (sJIA). Features of this syndrome are haemophagocytosis in the bone marrow, pancytopenia, hepatosplenomegaly, lymphadenopathy, and failure of many organs. High levels of cytokines, such as $\operatorname{IFN} \gamma$, tumour necrosis factor $\alpha(\mathrm{TNF} \alpha)$, interleukin 1 (IL1), IL2, and IL6, produced by T cells and macrophages are detectable in the serum of patients. Since MAS occurred in patients transplanted with autologous bone marrow selected for CD34-positive cells, a reduction in the number of $\mathrm{T}$ cells might be responsible for uncontrolled macrophage activation leading to hypercytokinaemia and the abovementioned clinical features. We suggested that monocytes from patients with sJIA are hypersensitive to activating signals-for example, IFN $\gamma$.

Patients and methods-Monocytes from 9 patients with sJIA in various stages of disease and from 12 healthy controls were incubated with physiologically relevant concentrations of IFN $\gamma$ (ranging from $0.1 \mathrm{U} / \mathrm{ml}$ to $250 \mathrm{U} / \mathrm{ml}$ ) and the expression of CD64 on the cell surface by FACS as an indication for macrophage activation was analysed.

Results-Monocytes from the patients were hyperresponsive to concentrations of $\mathrm{IFN} \gamma$ starting from $10 \mathrm{U} / \mathrm{ml}$. These results were not due to different expression levels of the IFN $\gamma$ receptor 1 and 2 (CD119) on monocytes from patients and healthy controls. A possible explanation for our observation that patients' monocytes do not respond better to low IFN $\gamma$ concentrations $(0.1-1 \mathrm{U} / \mathrm{ml})$ than cells from controls might be that patients' monocytes are hyporesponsive to macrophagedeactivating cytokines. Interestingly, no hyperresponsiveness was found in monocytes of a successfully transplanted patient when exposed to IFN $\gamma$. As endogenous $\mathrm{TNF} \alpha$ production is essential in macrophage activation, it is interesting that we did not find a significant difference in expression of $\mathrm{TNF} \alpha$ receptors (CD120a and CD120b) on monocytes from patients and healthy controls.

Conclusion-Monocytes of patients with sJIA are hyperresponsive to IFN $\gamma$.

\subsection{Reactivity of synovial fluid mononuclear cells (SF MNC) to peptides derived from $E$ coli heat shock protein dnaJ or its human homologues in pauciarticular JIA (p-JIA)}

M MASSA ${ }^{\star}$, M PASSALIA $\dagger$, S VIOLA $\dagger$, F DE BENEDETTI†, BJ PRAKKEN $\ddagger$ A MARTINI†, S ALBANI

*Laboratorio Biotecnologie Tecnologie Biomediche, fClinica Pediatrica, IRCCS

Policlinico San Matteo, Universita'degli Studi di Pavia, Pavia, Italy, $\neq$ Department of Immunology, University Children Hospital, Utrecht, The Netherlands, $\uparrow$ Department of Pediatrics, University of California San Diego, USA

Background-Immune responses to heat shock proteins (hsp) may play a relevant part in induction and regulation of chronic inflammation.

Objective-To evaluate the proliferative responses and the production of both proinflammatory (interferon $\gamma(\mathrm{IFN} \gamma)$ and tumour necrosis factor $\alpha(\mathrm{TNF} \alpha)$ ), and antiinflammatory (interleukin 10 (IL10)) cytokines of synovial fluid mononuclear cells (SFMNC) and PBMNC from patients with p-JIA

Results-SFMNC showed higher proliferative responses and IFN $\gamma$ production than PBMNC when stimulated with the $E$ coli hsp
dnaJ. In 7 patients with a stimulation index $>5$ when stimulated with the whole $E$ coli hsp dnaJ, SFMNC were stimulated with 8 synthetic peptides derived from the $E$ coli hsp dnaJ, and with 9 peptides derived from those regions on three human hsp dnaJ (HDJ1, $\mathrm{HDJ} 2$, and HSJ1) presenting sequence homology with $E$ coli dnaJ, revealed by scanning non redundant NCBI databases using BLAST and FASTA softwares. All the peptides were selected by computerised prediction of peptide binding motifs to HLA class II molecules. All the $E$ coli dnaJ derived peptides induced proliferative responses; the production of IFN $\gamma$ was significantly correlated with that obtained after stimulation with the whole bacterial protein $(p<0.03$ by Spearman correlation test). A wide scattering of data was obtained for $\mathrm{TNF} \alpha$ production, while no production of IL10 was found after stimulation with each of the bacterial peptides. The human h2, h3, h5, and h164, h167, and h176 peptides derived from the human dnaJs induced a production of $\mathrm{IFN} \gamma$ and $\mathrm{TNF} \alpha$ comparable with that of their bacterial homologous peptides 4 and 174, respectively. The production of IL10 (3.8-44 pg/ml) was detectable only after stimulation with human peptides. Interestingly, the stimulation of SFMNC with the human peptides h20, h21, and h23, homologous to the bacterial peptide 22 , induced production of IFN $\gamma$ and $\mathrm{TNF} \alpha$, but no detectable levels of IL10 were found. Conclusion-These data suggest that a proinflammatory response to the $E$ coli hsp dnaJ confined to the synovial compartment may be perpetuated by relevant epitopes on its human homologues.

1.19 Abnormal regulation of interleukin 6 (IL6) production in systemic juvenile idiopathic arthritis (s-JIA): increased spontaneous production and reduced sensitivity to inhibition by IL10

P PIGNATTI, C MEAZZA, MVIVARELLI, A MARTINI,

\section{F DE BENEDETTI}

Clinica Pediatrica, IRCCS Policlinico San

Matteo, Universita' degli Studi di Pavia, Pavia, Italy

In patients with s-JIA, serum levels of IL6 are markedly increased during the active phase of disease and normal during remission. Excessive IL6 production appears to explain a large number of the clinical and biological features of this disease. However, the cause(s) of this overproduction is unknown. In this study we investigated the in vitro production of IL6 by peripheral blood mononuclear cells (PBMC) of patients with s-JIA and its regulation by IL10. IL10 is one of the so-called antiinflammatory cytokines and it is a powerful inhibitor of monocyte IL6 production. PBMC from 15 patients with s-JIA and 10 healthy controls were cultured for $24 \mathrm{~h}$ in the absence or presence of lipopolysaccharide (LPS, $100 \mathrm{ng} / \mathrm{ml}$ ) and of increasing amounts of IL10 $(0.3,1,3 \mathrm{ng} / \mathrm{ml})$. IL6 levels in the supernatant were measured by ELISA. The production of IL6 by PBMC in the absence of LPS was significantly $(\mathrm{p}<0.002)$ higher in patients $(17(\mathrm{SD} 2.04) \mathrm{ng} / \mathrm{ml})$ than in controls $(0.12(0.13))$. In the presence of LPS IL6 production was comparable in patients (9.12 (5.07) $\mathrm{ng} / \mathrm{ml})$ and controls (9.00 (2.93)). The IL10 concentration which inhibited IL6 production by $50 \%$ was significantly $(\mathrm{p}<0.05)$ higher in patients than in controls. In patients with s-JIA basal IL6 production was significantly correlated with the concentration of IL10 necessary to obtain a 
$50 \%$ inhibition of LPS-induced IL6 production $(r=0.835, p<0,001)$.Confirming this correlation, when patients were divided on the basis of their basal IL6 production, in patients with a basal IL6 production $>500$ $\mathrm{pg} / \mathrm{ml}$ the $50 \%$ inhibiting dose of IL10 was significantly $(\mathrm{p}=0.03)$ higher (1.62 (1.05) $\mathrm{ng} / \mathrm{ml}$ ) than in patients with a basal IL6 production $<500 \mathrm{pg} / \mathrm{ml}(0.37(0.17) \mathrm{ng} / \mathrm{ml})$. In vitro production of IL10 was found to be comparable in patients and controls, in the absence or in the presence of LPS stimulation. These results rule out the possibility that reduced sensitivity to exogenous IL10 might be due to a defect in IL10 production. The increased unstimulated production as well as the reduced inhibition by IL10 were not associated with the $\mathrm{G} / \mathrm{C}$ polymorphism at position -174 of the IL 6 promoter, which was recently suggested to be associated with s-JIA. In conclusion, our results indicate that PBMC of patients with s-JIA are activated to produce raised amounts of IL6 and are less sensitive to the inhibitory effect of IL10 on the production of IL6.

1.20 In vivo neutralisation of human IL6 (hIL6) achieved by immunisation of hIL6 transgenic mice with an hIL6 receptor antagonist

F DE BENEDETTI ${ }^{\star}$, P PIGNATTI ${ }^{\star}$, $M$ VIVARELLI*, C MEAZZA ${ }^{\star}, R$ SAVINO†, G CILIBERTO†, A MARTINI* *Dipartimento di Scienze Pediatriche, IRCCS $S$ Matteo, Universita' di Pavia, Pavia; IIRBM P Angeletti, Pomezia (Roma), Italy

Neutralisation of IL6 represents a possible therapeutic approach to chronic arthritis. In this study we investigated whether the antibody $(\mathrm{Ab})$ response to human IL6 (hIL6) induced by immunisation with the IL6 receptor antagonist Sant1 (an hIL6 variant with 7 amino acid substitutions) neutralised the clinical and biological effects of endogenous hIL6 overexpression in the hIL6 transgenic mice NSE/hIL6. In these mice overexpression of hIL6 causes a marked decrease in growth rate and in IGF-I levels.

To validate the approach we first immunised non-transgenic $\mathrm{CB} 6 \mathrm{~F} 1$ female mice with $100 \mu \mathrm{g} / \mathrm{ml}$ of Sant 1 in $\mathrm{Al}(\mathrm{OH})_{3}$ (SantImm) or with $\mathrm{Al}(\mathrm{OH})_{3}$ alone (All-Imm). Sant-Imm mice developed high titres of $\mathrm{Ab}$ to hIL6 (58 000 (19 595)), while All-Imm mice did not $(<500)$. After mating with NSE/hIL6 male mice, the transgenic offspring of SantImm female mice showed high titres of $\mathrm{Ab}$ to hIL6 (32 187 (9643)), acquired by transplacental transfer, total masking of antigenic hIL6, complete correction of the growth defect, and of IGF-I levels. Table 4 shows the results at age 8 days. To evaluate whether this could be obtained in the hIL6 transgenic mice, which are immunologically tolerant to the transgene product, the same immunisation protocol was used in NSE/hIL6 female mice. Sant-Imm NSE/hIL6 female mice developed even higher Ab titres to hIL6 (78 000 (2828)). The offspring of Sant-Imm NSE/hIL6 female mice showed total masking of antigenic hIL6, and complete correction of

Table 4 Results at age 8 days

\begin{tabular}{|c|c|c|c|c|}
\hline Offspring of: & $C B 6 F 1$ & $C B 6 F 1$ & $C B 6 F 1$ & $N S E / h I L-6$ \\
\hline Immunogen & Allumen Wild-Type & Allumen Transgenic & Sant1 Transgenic & Sant-1 Transgenic \\
\hline Body weight $(\mathrm{g})$ & $4.0(0.1)$ & $2.7(0.4)$ & $4.0(0.4)$ & $3.9(0.3)$ \\
\hline IGF-I (ng/ml) & $135 \quad(13)$ & $70 \quad(26)$ & $122 \quad(19)$ & $119 \quad(13)$ \\
\hline
\end{tabular}

the growth defect and of IGF-I levels (table 4). These results show that vaccination of hIL6 transgenic mice with Sant1 induces an $\mathrm{Ab}$ response to hIL6 which can completely neutralise in vivo the effects of a chronic endogenous overproduction of hIL6. This represents a possible therapeutic approach in IL6 mediated diseases.

\subsection{Functional characterisation of memory $T$ cells in juvenile idiopathic arthritis (JIA): possible strategies for} immunodeviation

I PRIGIONE $\dagger, S$ CHIESA $\dagger$, $S$ VIGNOLA ${ }^{\star}$, P PICCO ${ }^{\star}$,

A BUONCOMPAGNI ${ }^{\star}$, V PISTOIA M GATTORNO ${ }^{\star}$

*2nd Division of Paediatrics, +Laboratory of Oncology, "G Gaslini” Institute for Children, Genoa, Italy

Background-Memory $\mathrm{T}$ cells are thought to have a pivotal role in the perpetuation of chronic autoimmune disorders.

Objective-To investigate the functional activity of synovial fluid (SF) resting $\left(\mathrm{CD} 45 \mathrm{RO}^{+} \mathrm{CD} 27^{+}\right)$and effector $\left(\mathrm{CD} 45 \mathrm{RO}^{+} \mathrm{CD} 27^{-}\right) \mathrm{CD}^{+}+$memory $\mathrm{T}$ cells in comparison with peripheral blood (PB) correspondent cells in patients affected with JIA.

Patients and methods -7 patients with JIA (4 oligo, 3 poly) were studied. Cell separation of freshly isolated PB and SF mononuclear cells (MNC) was performed by negative selection using murine antihuman monoclonal antibody (mAb; CD45RA $\left.{ }^{+}, \mathrm{CD}^{+}, \mathrm{DR}^{+}\right)$. The purified $\mathrm{CD}^{+} \mathrm{CD} 45 \mathrm{RO}^{+} \mathrm{T}$ cells were subsequently stained with anti-CD27 mAb (Pharmingen, USA) and separated by adherence to Petri dishes coated with goat antimouse immunoglobulin. Intracellular interferon $\gamma$ (IFN $\gamma$ ) and interleukin 4 (IL4) were analysed by flow cytometry after $4 \mathrm{~h}$ stimulation with phorbol myristate acetate (20 $\mathrm{ng} / \mathrm{ml})$, ionomycin $(250 \mathrm{ng} / \mathrm{ml})$, and Brefeldin A $(5 \mu \mathrm{g} / \mathrm{ml})$. In two patients SF $\mathrm{CD} 27^{+}$and $\mathrm{CD} 27^{-}$memory $\mathrm{CD} 4+\mathrm{T}$ cells were plated with anti-CD3 (OKT3, hybridoma supernatants) in the presence of anti-CD28 mAb, rIL4 $(20 \mathrm{ng} / \mathrm{ml})$ and rIL2 $(10 \mathrm{U} / \mathrm{ml})$ for three days and subsequently revaluated for intracellular cytokines.

Results-SF $\mathrm{CD} 45 \mathrm{RO}^{+} \mathrm{CD} 27^{-}$and $\mathrm{CD} 27^{+}$ $\mathrm{CD} 4^{+} \mathrm{T}$ cells displayed a higher percentage of IFN $\gamma$ ((mean 32\%, range 5-51\%; 19\%, $2.5-40 \%$, respectively) than IL4 (9.4\%, $2-21 \% ; 10.2 \%, 2-27 \%$, respectively) positive cells when compared with correspondent $\mathrm{PB}$ $\mathrm{T}$ cells.

In 2 patients, stimulation of $\mathrm{SF}$ $\mathrm{CD} 4{ }^{+} \mathrm{CD} 45 \mathrm{RO}^{+} \mathrm{T}$ cells with anti-CD3 and anti-CD28 antibodies in the presence of rIL4 determined a clear shift toward a Th2-type phenotype, for both CD27 $7^{+}$(IFN $\gamma / \mathrm{IL} 4 \%$ positive cells: patient $1: 40 / 7 \Rightarrow 6 / 15$; patient 2 : $7 / 2.5 \Rightarrow 7 / 13$ ) and $\mathrm{CD} 27^{-}$(patient 1: 51/ $21 \Rightarrow 2 / 51$; patient $2: 5 / 4 \Rightarrow 2 / 11)$ subpopulations.

Conclusion-These preliminary data shed some light on the role of memory $\mathrm{T}$ cells in the pathogenesis of synovitis in JIA. Costimu- lation of $\mathrm{T}$ cell receptor and $\mathrm{CD} 28$ in the presence of IL4 seems to cause their activity to deviate.

\subsection{Low expression of CD14 in acute} rheumatic fever (ARF)

S CARRASCO, ALS HAYATA,

JAL KOCHEN,

C GOLGENSTEIN-SCHAINBERG

Rheumatology Division of Hospital das Clinicas Universty of São Paulo, Brazil

Objective-Acute rheumatic fever is a systemic inflammatory disease caused by group A $\beta$-haemolytic streptococcus (GABHS) Some authors have reported immunological alterations in ARF, mainly related to autoantibody production and its pathogenic role Meanwhile, few have reported aspects of the cellular immunology mechanisms involved in this disease. To evaluate cellular aspects that might play a part in its physiopathogenesis we studied 19 patients with ARF followed up at our paediatric rheumatology division and 10 normal controls matched for age and sex.

Methods and results-Peripheral blood mononuclear cells were isolated using a gradient density technique with Ficoll-Hypaque. Antigen surface expression of CD3, CD4, CD8, CD14, CD16, CD45 RA, CD45 RO, CD56, and CD 57 molecules was evaluated using specific monoclonal antibodies (Becton Dickinson (BD)). Flow cytometry analysis was performed with immunofluorescense acquisition in the FACScalibur (BD). Our results showed significantly lower expression of CD14 in patients with ARF than in controls ( $\mathrm{p}=0.009$, Mann-Whitney). No other statistical differences were shown.

Conclusion - CD14 recognises a $55 \mathrm{kDa}$ antigen that is expressed in mature human monocytes of peripheral blood. The low expression of CD14 in patients with ARF suggests that mechanisms related to antigenic presentation and its clearance might contribute to initiation and/or perpetuation of the immune alterations triggered by GABHS in ARF.

\subsection{Molecular diagnosis in the} Dutch-type periodic fever syndrome

JOOST FRENKE`, SANDER

M HOUTEN + , HANS R WATERHAM $\dagger$, RONALD JA WANDERS + , RIES DURAN $\rrbracket$, BWEETIEN POLL-THEף, WIETSE KUIS

Departments of ${ }^{\star}$ General Paediatrics, $\neq$ Paediatric Immunology, and $\mid$ Metabolic Disorders, Wilhelmina Children's Hospital, University Medical Centre, Utrecht,

tDepartments of Clinical Chemistry and Paediatrics, Emma Children's Hospital, Academic Medical Centre, Amsterdam Dutch-type periodic fever (MIM No 260920 ) is an autosomal recessive disease with recurrent attacks of high fever, headache, abdominal pain, diarrhoea, and/or arthralgias, accompanied by rashes, tender cervical lymphadenopathy, splenomegaly, and/or arthritis. Typically, serum IgD is raised, hence the original name hyper IgD periodic fever syndrome. No treatment has been consistently effective in this syndrome. Recently we identified its genetic cause: mutations in $M V K$, leading to severely reduced activity of the enzyme mevalonate kinase. We demonstrated mevalonate kinase deficiency in 16 patients with Dutch-type periodic fever, including 1 boy with persistently normal IgD. These patients had mutations in both $M V K$ alleles. In four patients 
with periodic fever and a high serum IgD, mevalonate kinase was genetically and enzymatically normal, ruling out Dutch-type periodic fever.

Conclusion - Children with unexplained recurrent fevers should be tested for mevalonate kinase deficiency irrespective of serum $\operatorname{IgD}$. Molecular diagnosis can positively identify patients with Dutch-type periodic fever and should serve as a starting point for future trials.

\subsection{RAG1+RAG2 expression in} peripheral $B$ and $T$ cells of patients with SLE

HJ GIRSCHICK ${ }^{\star}+$, T NANKI $†$, A GRAMMER†, PE LIPSKY†

${ }^{\star}$ Children's Hospital, University of Wuerzburg, Germany; † Simmons Arthritis Research Center, University of Texas, Dallas, USA

To analyse the potential for receptor replacement the expression of RAG1 and RAG2 mRNA was assessed in the peripheral blood $B$ cell populations and individual $\mathrm{B}$ cells obtained from patients with active systemic lupus erythematosus (SLE). Analysis of bulk mRNA by reverse transcriptase polymerase chain reaction (RT-PCR) showed RAG1 and RAG2 expression in peripheral $\mathrm{B}$ cells of patients with SLE, but not in normal subjects. Individual SLE B cells, assessed by single cell RT-PCR, showed 3 times more RAG1 and RAG2 ${ }^{+}$cells than normal subjects. $35-65 \%$ of double RAG ${ }^{+}$ SLE B cells expressed IgD mRNA, 50\% VpreB mRNA, but not IgG mRNA. These results indicate that the enzymes necessary for receptor replacement are present in peripheral $\operatorname{IgD}$ and $\mathrm{VpreB}^{+}$SLE B cells. These cells might represent premature bone marrow immigrants. $3 \%$ of peripheral SLE memory $\mathrm{T}$ cells were RAG1 and RAG2 ${ }^{+}$, whereas none was positive in normal subjects. The frequency tripled after $\alpha \mathrm{CD} 3$ stimulation in vitro. SLE memory $\mathrm{T}$ cells, like B cells, may have the ability to edit their $\mathrm{T}$ cell receptor in the periphery.

Supported by the DFG and the NIH, Grant AI 31229 .

\section{Classification of juvenile idiopathic arthritis}

2.1 Evaluation of classification criteria for juvenile idiopathic arthritis (JIA)

M LANGKAMMERER, R HÄFNER, R MORHART

Paediatric Rheumatology Hospital,

Garmisch-Partenkirchen

The new classification of JIA means a valuable contribution for international exchange. The definition of distinct categories enables studies of homogeneous groups of patients in the future. Our task at present is to validate the classification criteria.

We therefore categorised a total of 172 consecutive patients with JIA who were treated in our hospital in October 1999.

Results - 145 patients fulfilled criteria for one of the defined categories: 30 systemic JIA, 47 oligoarthritis (19 of them with extended oligoarticular course), 44 rheumatoid factor (RF) negative and 5 RF positive polyarthritis, 11 enthesitis related arthritis, and 8 psoriasis arthritis. 27 were classified as "other arthritides". 11 did not fulfil criteria for any one category, 16 fulfilled criteria for two categories. Double classification occurred mainly in patients with psoriasis or enthesitis.

Discussion-(1) 6 of the 11 patients who did not fit into one category could be classified as oligoarthritis, but a family history of psoriasis excluded them and criteria for psoriasis arthritis were not fulfilled.

(2) 5 of the 16 patients who met criteria for two categories could be classified in one (psoriasis arthritis) if psoriasis is an exclusion for oligoarthritis, RF negative polyarthritis, and enthesitis related arthritis. The other 11 patients had enthesitis and arthritis but also fulfilled criteria for either oligoarthritis or RF negative polyarthritis.

(3) 25 children categorised as RF negative polyarthritis had asymmetric arthritis of 5 to 8 joints at onset (18 of them with antinuclear antibodies, 7 with chronic uveitis), resembling oligoarthritis. We therefore suggest an extra category "extended oligoarthritis".

Conclusion-About $85 \%$ of our patients with JIA could readily be classified into one of the defined categories. With minor changes in the definition this percentage would increase to over $90 \%$. Introduction of a further category for extended oligoarthritis with asymmetric arthritis of 5 to 8 (9) joints at onset should be considered.

\subsection{Classification of juvenile idiopathic arthritis: suggestions to improve the efficacy of the Durban criteria}

FLAVIO FANTINI, VALERIA GERLONI, MAURIZIO GATTINARA, CRISTINA ARNOLDI

Chair of Rheumatology of the University of

Milan, Centre for Rheumatic Children, Gaetano Pini Institute, Milan, Italy

The Durban Classification Criteria for juvenile idiopathic arthritis (JIA) were tested on a cohort of 683 patients (220 male, 463 female) with juvenile onset primary chronic arthritides recorded in the database of our centre. 214 cases fell into the category of "other arthritis". To reduce the number of cases in this category, two ways were suggested to $(a)$ reduce the exclusions and $(b)$ to consider a hierarchy of the categories.

According to the data of our patients, the exclusions which most commonly hinder an obvious classification are (a) family history of psoriasis in at least one first or second degree relative (for oligoarthritis); (b) psoriasis confirmed by a dermatologist in at least one first or second degree relative (for enthesitis related arthritis); (c) oligoarticular onset for rheumatoid factor (RF) positive polyarthritis.

The hierarchy principle states that if a patient fits into more than one category, he or she should be attributed to the category with the highest rank. In attributing ranks, two general principles might be taken into account: $(a)$ the more severe form should be preferred to the less severe one; $(b)$ the more differentiated form (that is better biologically and/or clinically characterised) should be preferred to the less differentiated one. According to our data the most useful ranking might be: (1) systemic arthritis; (2) RF positive polyarthritis; (3) psoriatic arthritis; (4) enthesitis related arthritis; (5) oligoarthritis; (6) RF negative polyarthritis.

Table 1 Patients classified according to the Durban criteria

\begin{tabular}{llllllll}
\hline & Oligo & $\begin{array}{l}\text { Poly } R F \\
(-)\end{array}$ & $\begin{array}{l}\text { Poly } R F \\
(+)\end{array}$ & Sys & ErA & Pso & Other \\
\hline $\begin{array}{l}\text { paJCA (n=59) } \\
\text { poJCA (n=25) }\end{array}$ & $47^{\star}$ & 25 & 2 & & 1 & & 11 \\
$\begin{array}{l}\text { po-RF+ (n=2) } \\
\text { sJCA (n=18) }\end{array}$ & & & 2 & 18 & & & \\
JSp (n=17) & 2 & & & 13 & 1 & 3 \\
PsA (n=4) & & 25 & & 2 & \\
\hline
\end{tabular}

* 35 with persistent oligoarthritis and 12 with extended oligoarthritis
If the hierarchy principle were accepted, slightly modified Durban criteria would classify almost all patients with JIA and each cat-

2.3 Evaluation of Durban Classification
Criteria for juvenile idiopathic arthritis (JIA) in Spanish children

R MERINO*, J DE INOCENCIO†, J GARCÍA-CONSUEGRA ${ }^{\star}$

*Hospital Universitario "La Paz" y

Estrecho de Corea, Madrid, Spain

Objective-To test the proposed Durban Classification Criteria for juvenile idiopathic arthritis (JIA) in a cohort of Spanish children. Methods - 125 patients seen between January 1999 and March 2000 were classified according to the following criteria: EULAR for pauciarticular (paJCA), polyarticular (poJCA), poJCA RF positive (po-RF+), and systemic (sJCA) arthritis; Vancouver for psoriatic arthritis (PsA); and ESSG for juvenile spondyloarthropathy (JSp). Patients were reclassified according to Durban criteria, and their clinical/ serological characteristics were reviewed.

Results-Table 1 shows the results obtained. Discussion-Application of Durban criteria results in a significant number of unclassified patients. According to these criteria, 14/125 of our patients $(11 \%)$ fell into the "other arthritis" category, 13/14 because of a positive family history of psoriasis.

Interestingly, a 2nd degree family history of psoriasis does not fit the "psoriatic arthritis" criteria, but allows classification of patients into the "poly RF negative" category.

No differences were found in any variable studied between patients classified as "oligo" $(n=47)$ and those with oligoarticular onset included in "other arthritis" group ( $\mathrm{n}=11)$, except for a family history of psoriasis.

\subsection{JCA in the Nordic countries; a} population based multicentre study of construct validity of ILAR, in comparison with EULAR classification criteria

LILLEMOR BERNTSON, FOR THE NORDIC STUDY GROUP OF PAEDIATRIC RHEUMATOLOGY

Department of Paediatrics, University of Göteborg and Falun's Hospital, Sweden Background - Childhood chronic arthritis is a heterogeneous group of disorders. New classification criteria (ILAR), for "juvenile idiopathic arthritis" (JIA), have been proposed. They are more descriptive than those formerly used (ACR-JRA, EULAR-JCA) but need validation under "appropriate epidemiological and statistical direction against classifications already in use".

Objective-To compare construct validity of ILAR and EULAR classification criteria in a cohort of prospectively collected incidence cases of "juvenile chronic arthritis" within 15 defined areas of Sweden, Finland, Norway, egory would maintain a fruitful and valuable homogeneity. 